\title{
New Media Literacies of Communication Students
}

\author{
Jale Balaban-Sali \\ Anadolu University, Turkey
}

\begin{abstract}
This study examined new media literacy skills of university students based on Jenkins and his colleagues' classification. Toward this purpose, an online Likert scale was administered to a sample $(n=170)$. This scale included a multi-component understanding of media literacy such as tackling the consumption of media messages and the original creation of multimedia material. The Cronbach's Alpha reliability coefficient of the scale was 0,93 . The instrument was structured around three main sections; demographics, media use characteristics, and new media literacies (NMLs). The third section aimed to assess participants' new media literacy skills by presenting them 60 items about their social and cultural modes of engagement, online interaction, and media consumption and creation patterns. The statements were conceptually built around the $12 \mathrm{NMLs}$ skills identified by Jenkins and his colleagues. These skills are: Play, appropriation, distributed cognition, collective intelligence, judgment, transmedia navigation, networking, negotiation, and visualization. The results of the study showed that individuals who spent more time on Internet, social media, and blogging had the highest NMLs levels. Furthermore, young participants' NMLs levels were higher than those over the age of 32.
\end{abstract}

Keywords: New media literacies; Social media skills; New media literacy assessment; Digital literacies; Measuring new literacies

\section{Introduction}

New media has become a critical part of our everyday life. In the past ten years, we have seen the emergence of platforms like Facebook, and MySpace (social networking sites), Wordpress and Blogger (blogging), Twitter (microblogging), YouTube (video sharing), and Wikipedia (wikibased encyclopedia). They have been changing everything from the ways people work, to the ways they communicate with each other and spend their leisure time (Kellner, 2002). We are able to communicate through social media, search for information, play games, participate in political discussions or create new media content. The media consumer can become a 'prosumer' thanks to the proliferation of Web 2.0 platforms (Jenkins et al., 2006).

Researchers have argued that the concept of literacy has evolved historically from traditional literacy (interpreting symbols, communication, and understanding etc.) to digital literacy (mostly related to Internet and participatory culture). After 'visual literacy,' 'technological literacy,' 'computer literacy,' and 'information literacy' ultimately proved unsuccessful, many sought to find a new term more in keeping with digital communications and the Internet age (Belshaw, 2011, p.83).

Coiro, Knobel, Lankshear, and Leu (2008) also addressed different kinds of new literacies. Some of these variations are terminological. Different terms, like 21st century literacies, 
Internet literacies, digital literacies, new media literacies, multi literacies, information literacy, ICT literacies, computer literacy and so on, are used to refer to under the 'new literacies' umbrella. There is not one defined version of new literacies that is dominant everywhere around the world. However, Leu and his colleagues (2007) describe four characteristics of the 'new literacies'. First, emerging ICT tools, applications, media, and environments require novel skills, strategies, and dispositions for their effective use. Second, new literacies are central to full economic, civic, and personal participation in a globalized society. Third, new literacies constantly evolve as their defining ICT continuously are renewed through innovation. Fourth, new literacies are multiple, multimodal, and multifaceted.

International ICT Literacy Panel (2002) emphasized that new information and communication technologies (ICTs), such as the Internet, wikis, blogs, search engines, instant messaging, email, and online gaming worlds require new literacies, which all have become important new contexts for literacy, learning, and life in general. As writer Alvin Toffler points out, "The illiterate of the 21st century will not be those who cannot read and write, but those who cannot learn, unlearn, and relearn."

In this article, the concept of "new media literacies" was used instead of new literacies. Information literacy has typically been associated with research skills. Media literacy typically has been associated with critical analysis of news, advertising and mass media entertainment. Health media literacy has been associated with exploring media's impact on making positive choices related to nutrition, exercise, body image, violence and substance abuse prevention. New media literacy is associated with the ability to use computers, social media, and the Internet (Hobbs, 2010). The emphasis is not just on how people respond to media messages, but also on how they engage proactively in a media world where production, participation, social group formation, and high levels of nonprofessional expertise are prevalent (Gee, 2010, p.36).

New media literacy can be defined as "ability to critically assess and develop content that uses new media forms, and to leverage new media for persuasive communication" (Davies, Fidler, \& Gorbis, 2011). New technologies and tools, video production, digital animation, transmedia navigation, and augmented reality etc. have created a need for new media literacies beyond traditional media literacy. Individuals need to become fluent in critically reading, assessing, and creating new media forms. Shortly, Livingstone (2005) also stated that as technologies converge, skills converge as well, and so we need a convergent notion of literacy.

The changes in technology, media, and society require the development of critical media literacy to empower students and citizens to adequately read media messages and produce media themselves in order to be active participants in a democratic society (Kellner \& Share, 2005,2007, p.3). Simsek and Simsek (2012, p.274) also indicated that democratic culture and values are strongly related with digital literacy skills. Citizens could be aware of their environment by appropriately creating, using, responding, forwarding, sharing, achieving, and new media contents. Democratic participation and active citizenship are developed by multimodal and multifaceted channels. Lifelong learning and personal fulfillment opportunities may be improved by new literacies.

Kellner $(2002$, p.93) emphasized that critical media literacy not only teaches students to learn from media, to resist media manipulation, and to use media materials in constructive ways, but is also concerned with developing skills that will help create good citizens and that will make them more motivated and competent participants in social life. 
In Confronting the Challenges of Participatory Culture: Media Education for the 21st Century, Jenkins, Clinton, Purushatma, Robison, and Weigel (2006) describe this new environment as a 'participatory culture'. According to this report, a participatory culture has the following characteristics: Low barriers for artistic expression and civic engagement, strong support for creating and sharing, informal mentorship whereby experienced users pass their knowledge on to novices, an atmosphere that encourages a sense that contributions matter, and an opportunity for social connection.

Jenkins and his colleagues (2006) argue that the concept of media literacy becomes an increasingly vital for media consumption and media production for full participation in today's digital environment. They make a critical theoretical contribution by identifying twelve 'new media literacies' (NMLs) that are necessary for a full participation in today's media environment. These skills are: Play, performance, simulation, appropriation, multitasking, distributed cognition, collective intelligence, judgment, transmedia navigation, networking, negotiation, and visualization (Jenkins et al., 2006). They state that these skills are required for full and meaningful participation in the information society.

The NML framework differs from previous media literacy models. People are active participants in the new digital environment. Jenkins and his colleagues also claim that the focus of literacy has shifted from individual expression to community involvement. Working together with others has become much more important. Jenkins' 12 new media literacy skills are below:

Play: The capacity to experiment with one's surroundings as a form of problem-solving.

Performance: The ability to adopt alternative identities for the purpose of improvisation and discovery.

Simulation: The ability to interpret and construct dynamic models of real-world processes.

Appropriation: The ability to meaningfully sample and remix media content.

Multitasking: The ability to scan one's environment and shift focus as needed to salient details.

Distributed cognition: The ability to interact meaningfully with tools that expand mental capacities.

Collective intelligence: The ability to pool knowledge and compare notes with others toward a common goal.

Judgment: The ability to evaluate the reliability and credibility of different information sources.

Transmedia navigation: The ability to follow the flow of stories and information across multiple modalities.

Networking: The ability to search for, synthesize, and disseminate information.

Negotiation: The ability to travel across diverse communities, discerning and respecting multiple perspectives, and grasping and following alternative norms.

Visualization: The ability to interpret and create data representations for the purposes of expressing ideas, finding patterns, and identifying trends. 
Each of these skills represents a principle or approach to learning. NML plans to highlight the following emerging skills and practices: Affiliations (memberships, formal and informal, in online communities such as Facebook); expressions (producing new creative forms such as digital sampling, fan videomaking, fan fiction writing, zines, mash-ups); collaborative problemsolving (working together in teams, formal and informal, to complete tasks and develop new knowledge such as Wikipedia); circulations (shaping the flow of media such as podcasting, blogging) are forms of participatory culture (Jenkins et al., 2006). That is, media consumption is changing by user generated communication.

Research in Turkey points out that $32 \%$ of the Turkish people own a desktop computer, $27 \%$ have portable computer, $47 \%$ have an Internet connection, and $93 \%$ own a mobile phone. The Internet usage is especially frequent among adolescents (TUIK, 2012). It is clear that a life without computerized technologies is difficult to imagine in any contemporary society. In order to participate responsibly in the 21st century's societal life actively, it is assumed that critical new media literacy is essential for all individuals.

New media literacy is a relatively new research subject for the Turkish scholars and very few studies have been conducted so far. Most of the researchers working in this are from the field of communication. It is partly because communication professionals including students are assumed to adapt and use new technologies faster and more than the people in other fields. This implies that they should be more capable of using new media. For this reason, this study was conducted with participants from one of the communication faculties in Turkey, which provides state-of-the-art technological opportunities for its students.

The purpose of the study was to assess new media literacy skills based on Jenkins and his colleagues' twelve new media literacy skills in the Turkish context. Toward this purpose, the following research questions were investigated: (a) What are the NML levels of participants? (b) Are there any significant differences in participants' NML scores with regard to age, gender, and education level? (c) Are there any significant differences in participants' NML scores and their media use characteristics?

\section{Sample}

\section{Methods}

The sample included a total of 170 respondents. It was a convenient sample of volunteers over the age of 18 . In terms of gender, $49 \%$ of the participants were female and $51 \%$ were male. With regard to age groups; $32 \%$ of participants were from 18 to 22 age group; $34 \%$ were from 23 to 27 age group; $16 \%$ were from 28 to 32 age group and $18 \%$ of participants were from the ages over 33 . With regard to their educational level, $77 \%$ had bachelor's degree and $23 \%$ had advanced degree (master's and Ph.D. degrees).

More than half of the participants are in the age group of 18-27. Although the Internet usage of this group is very high, it is not enough to assume that participants are "digital natives". New media is not automatically learned. New media literacy education is the process of teaching and learning about new media. Therefore, the participants' new media literacy level is investigated in this study. 
The participants' demographic information was provided with regard to gender, and age in Table 1.

Table 1. Demographics of the Participants

\begin{tabular}{lcccccc}
\hline & \multicolumn{2}{c}{ Female } & \multicolumn{2}{c}{ Male } & \multicolumn{2}{c}{ Total } \\
\hline Age & $\mathrm{n}$ & $\%$ & $\mathrm{n}$ & $\%$ & $\mathrm{n}$ & $\%$ \\
\hline 18 to 22 & 31 & 36,9 & 24 & 27,9 & 55 & 32,4 \\
23 to 27 & 24 & 28,6 & 34 & 39,5 & 58 & 34,1 \\
28 to 32 & 13 & 15,5 & 14 & 16,3 & 27 & 15,9 \\
Over 33 & 16 & 19 & 14 & 16,3 & 30 & 17,6 \\
Total & 84 & 100 & 86 & 100 & 170 & 100 \\
\hline
\end{tabular}

\section{Instrumentation}

In order to measure NML, a Likert-type scale originally developed by Literat (2011) was administered to the sample. The researcher requested permission from the author to use and/or modify the survey instrument for this study. This scale translated into Turkish by three bilingual experts at Anadolu University and it was pilot-tested. This Likert-type scale includes a multi-component understanding of media literacy such as tackling the consumption of media messages and the original creation of multimedia material.

The survey instrument was structured around three main sections: Demographics, media use characteristics and new media literacies (NMLs). The demographic section contained three questions, asking participants about their gender, age, and level of education.

The second section contained six questions, asking their media use characteristics. These questions asking participants about their number of hours per day spend each of following activities: Surfing the Internet, watching television, reading print media, playing digital games (on mobile phone, computer, and console), activities on the social networking sites (Facebook, YouTube, Twitter etc.) and blogging (Wordpress, BlogSpot, Blogger etc.).

Finally, survey's third section aimed to assess participants' new media literacy skills (NMLs) through 60 items about their online activities and media consumption. These statements were conceptually built around the $12 \mathrm{NML}$ skills identified by Jenkins and his colleagues. These categories and sample items for each are as follows:

Play: "I have taught myself something new on a computer by seeing what happens when I play around with it"

Simulation: "I would like to participate in a simulation of something I cannot experience in real life, like flying a space shuttle to the moon or piloting a fighter jet"

Performance: "I have often taken on a different identity in order to experience something new or to solve a problem"

Appropriation: "I have created something new that incorporates stuff from popular culture, like writing a short story based on a character in my favorite book, making a fan video, or a music remix" 
Distributed cognition: "I find it important to use tools like spell check, a calculator, encyclopedia, etc. to help me in my learning or work"

Multitasking: "I manage to do my work successfully while doing other things like listening to music or texting"

Collective intelligence: "I enjoy the collaborative aspect of things like Wikipedia, team games, online fan communities, community message boards, etc."

Judgment: "When I search for something online and I get thousands of results, I can effectively decide which ones will be the most useful for me"

Transmedia navigation: "I'm happy that I can learn about my favorite things in different ways (on TV, on the internet, on Facebook, etc.)"

Networking: "When I go online, I like to feel like I am part of a community"

Negotiation: "I have learned something new about another culture from surfing the internet, playing online games, participating in online communities or forums, etc."

Visualization: "I think I am pretty good at understanding information from images, graphs, diagrams and other visual tools"

There were five statements for each NML of the scale, making a total of 60 items. The items were answered based on a 5 -point scale ( $1=$ Strongly Disagree, $5=$ Strongly Agree). The overall Cronbach's Alpha reliability coefficient for the entire scale was calculated to be 0.93 . The reliability coefficients of the sub-categories ranged between 0.60 and 0.84 .

\section{Procedures}

Data collection was carried out during June 2012. The online instrument was designed in Google Docs website and the link was distributed via e-mail and social networking sites, primarily Facebook and Twitter. On the first page of the online instrument, respondents were informed that participation is completely voluntary, that they may withdraw at any time, and the answers would be anonymous. It contained 69 randomized questions and took about 15 to 20 minutes to complete. The responses were downloaded as a data file. Some participants $(n=14)$ did not complete the new media literacy section of the survey so that their scores were excluded from the analysis. The remaining data $(\mathrm{N}=170)$ was then analyzed using SPSS 20 statistics software.

\section{Findings}

In order to analyze data toward the research questions, both descriptive and inferential statistical techniques were used in the study. The findings produced through these techniques were depicted in relevant tables and their interpretations were presented in corresponding paragraphs.

A descriptive statistics of the NMLs scale was presented in Table 2. The overall mean of NMLS scores $(M=3.64, S D=0.51)$ were considered 66 out of 100 . Total NML scores of participants were slightly higher than the score. Multitasking $(M=3.80, S D=0.78)$, collective intelligence $(M=4.00, S D=0.71)$, judgment $(M=4.26, S D=0.66)$, transmedia navigation $(M=3.79, S D=0.74)$ 
and visualization $(\mathrm{M}=4.05, \mathrm{SD}=0.80)$ scores were higher than the mean score. In other words, participants' judgment, visualization, collective intelligence, and multitasking skills respectively were higher than others. The lowest score was appropriation score $(M=2.94, S D=0.84)$. Performance score $(M=3.02, S D=0.65)$ of participants was also lower than the mean score.

Table 2. Descriptive Statistics of NMLs Scale

\begin{tabular}{|l|c|c|c|c|c|}
\hline & $\mathrm{n}$ & Minimum & Maximum & Mean & Std.Dev. \\
\hline Play & 170 & 1,40 & 5,00 & 3,47 & 0,75 \\
\hline Simulation & 170 & 1,40 & 5,00 & 3,64 & 0,80 \\
\hline Performance & 170 & 1,20 & 4,60 & 3,02 & 0,65 \\
\hline Appropriation & 170 & 1,20 & 5,00 & 2,94 & 0,84 \\
\hline Distributed Cognition & 170 & 1,60 & 5,00 & 3,63 & 0,70 \\
\hline Multitasking & 170 & 1,20 & 5,00 & 3,80 & 0,78 \\
\hline Collective Intelligence & 170 & 1,60 & 5,00 & 4,00 & 0,71 \\
\hline Judgment & 170 & 1,20 & 5,00 & 4,26 & 0,66 \\
\hline Transmedia Navigation & 170 & 1,00 & 5,00 & 3,79 & 0,74 \\
\hline Networking & 170 & 1,00 & 5,00 & 3,46 & 0,90 \\
\hline Negotiation & 170 & 1,00 & 5,00 & 3,64 & 0,90 \\
\hline Visualization & 170 & 1,00 & 5,00 & 4,05 & 0,80 \\
\hline Total NMLs & 170 & 1.97 & 4,78 & 3,64 & 0,51 \\
\hline
\end{tabular}

An analysis of variance summary of demographic data as independent variable and NMLs as dependent variable were provided in Table 3 . In this table only significant differences were presented and interpreted. The Tukey A post-hoc criterion was used in post-hoc analysis.

Table 3. Analysis of Variance Summary of Demographic Data as Independent Variable and NMLs as Dependent Variable ( $V=$ significant difference)

\begin{tabular}{|l|c|c|c|c|c|c|c|c|c|}
\hline & Gender & Age & $\begin{array}{c}\text { Level of } \\
\text { Education }\end{array}$ & $\begin{array}{c}\text { Time } \\
\text { spent } \\
\text { Internet }\end{array}$ & $\begin{array}{c}\text { Time } \\
\text { spent } \\
\text { TV }\end{array}$ & $\begin{array}{c}\text { Time } \\
\text { spent } \\
\text { reading }\end{array}$ & $\begin{array}{c}\text { Time } \\
\text { spent } \\
\text { social } \\
\text { media }\end{array}$ & $\begin{array}{c}\text { Time } \\
\text { spent } \\
\text { blogging }\end{array}$ & $\begin{array}{c}\text { Time } \\
\text { spent } \\
\text { digital } \\
\text { game }\end{array}$ \\
\hline Play & $\mathrm{V}$ & $\ldots$ & $\ldots$ & $\mathrm{V}$ & $\mathrm{V}$ & $\ldots$ & $\ldots$ & $\ldots$ & $\mathrm{V}$ \\
\hline Simulation & $\ldots$ & $\mathrm{V}$ & $\ldots$ & $\ldots$ & $\ldots$ & $\ldots$ & $\ldots$ & $\mathrm{V}$ & $\mathrm{V}$ \\
\hline Performance & $\ldots$ & $\mathrm{V}$ & $\ldots$ & $\mathrm{V}$ & $\ldots$ & $\ldots$ & $\mathrm{V}$ & $\ldots$ & $\mathrm{V}$ \\
\hline Appropriation & $\ldots$ & $\mathrm{V}$ & $\mathrm{V}$ & $\ldots$ & $\ldots$ & $\ldots$ & $\mathrm{V}$ & $\ldots$ & $\ldots$ \\
\hline D. Cognition & $\ldots$ & $\ldots$ & $\ldots$ & $\ldots$ & $\ldots$ & $\ldots$ & $\ldots$ & $\ldots$ & $\ldots$ \\
\hline Multitasking & $\ldots$ & $\ldots$ & $\ldots$ & $\mathrm{V}$ & $\ldots$ & $\ldots$ & $\ldots$ & $\mathrm{V}$ & $\ldots$ \\
\hline C. Intelligence & $\ldots$ & $\ldots$ & $\ldots$ & $\ldots$ & $\ldots$ & $\ldots$ & $\ldots$ & $\ldots$ & $\ldots$ \\
\hline Judgment & $\ldots$ & $\ldots$ & $\ldots$ & $\ldots$ & $\ldots$ & $\mathrm{V}$ & $\ldots$ & $\ldots$ & $\ldots$ \\
\hline T. Navigation & $\ldots$ & $\mathrm{V}$ & $\ldots$ & $\ldots$ & $\ldots$ & $\ldots$ & $\mathrm{V}$ & $\mathrm{V}$ & $\ldots$ \\
\hline Networking & $\ldots$ & $\ldots$ & $\ldots$ & $\mathrm{V}$ & $\ldots$ & $\ldots$ & $\mathrm{V}$ & $\ldots$ & $\ldots$ \\
\hline Negotiation & $\ldots$ & $\mathrm{V}$ & $\ldots$ & $\mathrm{V}$ & $\ldots$ & $\ldots$ & $\mathrm{V}$ & $\ldots$ & $\mathrm{V}$ \\
\hline Visualization & $\ldots$ & $\ldots$ & $\ldots$ & $\ldots$ & $\ldots$ & $\ldots$ & $\ldots$ & $\ldots$ & $\ldots$ \\
\hline Total NMLs & $\ldots$ & $\mathrm{V}$ & $\ldots$ & $\mathrm{V}$ & $\ldots$ & $\ldots$ & $\mathrm{V}$ & $\mathrm{V}$ & $\ldots$ \\
\hline
\end{tabular}


With regard to play scores of participants; the difference between play scores and gender was significant $[\mathrm{F}(1,168)=4.250, \mathrm{p}<.05]$. Females had lower play scores than males. The difference between play and time spent on Internet was significant $[\mathrm{F}(1,166)=3.196, \mathrm{p}<.05]$. Post-hoc analyses using the Tukey post-hoc criterion for significance indicated that participants who used Internet over 4 hours a day $(M=3.62, S D=0.78)$ significantly had higher play scores than who used 2 to 3 hours ( $M=3.26, S D=0.69$ ).

The difference between play and time spent on watching television was significant $[\mathrm{F}(1,166)=3.447, \mathrm{p}<.05]$. Post-hoc analyses indicated that participants who were watching television over 3 hours a day $(M=3.07, S D=0.87)$ significantly had higher play scores than who were watching 2 to 3 hours $(M=3.72, S D=0.70)$.

Further, an analysis of variance showed that time spent on digital game was significant on play scores $[\underline{E}(1,166)=3.402, \underline{p}<.05]$. Post-hoc analyses indicated that participants who played digital game over 2 hours a day $(M=4.00, S D=0.58)$ significantly had higher play scores than who did not play game $(M=3.33, S D=0.73)$.

The difference between simulation scores and participants' age was significant $[\underline{F}(1,166)=2.761, \underline{p}<.05]$. Post-hoc analyses indicated that participants whose age group was 18 to 22 years $(M=3.80, S D=0.78)$ significantly had higher simulation scores than age of over 32 $(\mathrm{M}=3.29, \mathrm{SD}=0.70)$.

An analysis of variance showed that time spent on blogging was significant on simulation scores $[\underline{F}(1,167)=3.198, \underline{p}<.05]$. Post-hoc analyses indicated that participants who were blogging over 1 hour a day $(M=3.95, S D=0.82)$ significantly had higher simulation scores than who were not interested in blogging $(M=3.49, S D=0.75)$. Besides, an analysis of variance showed that time spent on digital game was significant on simulation scores $[\underline{F}(1,166)=3.456$, p <.05]. Post-hoc analyses indicated that participants who played digital game less than 1 hour a day $(M=3.80, S D=0.70)$ significantly had higher simulation scores than who did not play game $(\mathrm{M}=3.46, \mathrm{SD}=0.79)$.

The difference between performance scores and participants' age was significant $[\underline{F}(1,166)=5.358, \underline{p}<.05]$. Post-hoc analyses indicated that participants whose age group was 18 to 22 years $(M=3.17, S D=0.62)$ significantly had higher performance scores than age of over 32 $(\mathrm{M}=2.62, \mathrm{SD}=0.71)$.

The difference between performance and time spent on Internet was significant $[\mathrm{F}(1,166)=4.144, \mathrm{p}<.05]$. Post-hoc analyses using the Tukey post-hoc criterion for significance indicated that participants who used Internet over 4 hours a day $(M=3.13, S D=0.66)$ significantly had higher performance scores than who used 3 to 4 hours ( $M=2.72, S D=0.57$ ). The difference between performance and time spent on social media was significant $[\underline{E}(1,166)=3.353, \underline{p}<.05]$. Post-hoc analyses indicated that participants who spent time on social media 2 to 3 hours a day $(M=3.17, S D=0.65)$ significantly had higher performance scores than who used less than 1 hour ( $M=2.76, S D=0.66)$. Also, an analysis of variance showed that time spent on digital game was significant on performance scores $[\underline{F}(1,166)=6.030, \underline{p}<.01]$. Post-hoc analyses indicated that participants who played digital game more than 2 hours a day $(M=3.42$, $S D=0.53)$ significantly had higher performance scores than who did not play game $(M=2.83$, $\mathrm{SD}=0.63)$. 
The difference between appropriation scores and participants' age was significant $[\underline{F}(1,166)=4.955, \underline{p}<.05]$. Post-hoc analyses indicated that participants whose age group was 18 to 22 years $(M=3.08, S D=0.76)$ significantly had higher appropriation scores than age of over $32(\mathrm{M}=2.49, \mathrm{SD}=0.78)$.

An analysis of variance showed that highest level of education achieved was significant on appropriation scores $[\mathrm{F}(1,167)=3.339, \underline{\mathrm{p}}<.05]$. Post-hoc analyses indicated that participants who had a bachelor's degree $(M=3.05, S D=0.85)$ significantly had higher appropriation scores than who had an advanced degree $(\mathrm{M}=2.73, \mathrm{SD}=0.84)$.

After all, the difference between appropriation and time spent on social media was significant $[\underline{F}(1,166)=2.950, \underline{p}<.05]$. Post-hoc analyses indicated that participants who spent time on social media over 3 hours a day $(M=3.18, S D=0.84)$ significantly had higher appropriation scores than who used less than 1 hour $(M=2.70, S D=0.88)$.

As seen in Table 3, an analysis of variance tests were conducted on distributed cognition, collective intelligence and visualization with demographic data as independent variable, but there were not statistically significant difference.

The difference between multitasking and time spent on Internet was significant $[\mathrm{F}(1,166)=2.973, \underline{p}<.05]$. Post hoc analyses indicated that participants who used Internet over 4 hours a day $(M=3.95, S D=0.75)$ significantly had higher multitasking scores than who used Internet 2 to 3 hours $(M=3.55, S D=0.89)$. An analysis of variance showed that time spent on blogging was significant on multitasking scores $[\mathrm{F}(1,167)=7.048, \mathrm{p}<.01]$. Post-hoc analyses indicated that participants who were blogging over 1 hour a day $(M=4.25, S D=0.60)$ significantly had higher multitasking scores than who were not interested in blogging $(M=3.58$, $\mathrm{SD}=0.83)$.

The difference between judgment and time spent on reading print media was significant $[\mathrm{F}(1,167)=4.994, \mathrm{p}<.05]$. Post-hoc analyses indicated that participants who were reading 2 to hours a day $(M=4.54, S D=0.56)$ significantly had higher judgment scores than who were reading less than 1 hour ( $M=4.10, S D=0.72)$.

The difference between transmedia navigation scores and participants' age was significant $[\mathrm{F}(1,166)=4.026, \mathrm{p}<.05]$. Post-hoc analyses indicated that participants whose age group was 18 to 22 years $(M=3.97, S D=0.62)$ significantly had higher transmedia navigation scores than age of over 32 ( $M=3.41, S D=0.77)$. The difference between transmedia navigation and time spent on social media was significant $[\underline{F}(1,166)=5.976, \underline{p}<.01]$. Post-hoc analyses indicated that participants who spent time on social media over 3 hours a day $(M=3.93, S D=0.70)$ significantly had higher transmedia navigation scores than who used less than 1 hour ( $M=3.42, S D=0.85)$. Finally, an analysis of variance showed that time spent on blogging was significant on transmedia navigation scores $[\mathrm{F}(1,167)=4.415, \underline{\mathrm{p}}<.05]$. Post-hoc analyses indicated that participants who were blogging over 1 hour a day $(M=4.12, S D=0.68)$ significantly had higher transmedia navigation scores than who were not interested in blogging $(M=3.62, S D=0.67)$.

The difference between networking and time spent on Internet was significant $[\underline{E}(1,166)=6.372, \underline{p}<.01]$. Post-hoc analyses indicated that participants who used Internet over 4 hours a day $(M=3.65, S D=0.75)$ significantly had higher networking scores than who used Internet 2 to 3 hours $(M=2.94, S D=0.80)$. The difference between networking and time spent on social media was significant $[\underline{F}(1,166)=8.822, \underline{p}<.01]$. Post-hoc analyses indicated that 
participants who spent time on social media over 3 hours a day $(M=3.87, S D=0.70)$ significantly had higher networking scores than who used less than 1 hour $(M=2.94, S D=0.97)$.

The difference between negotiation scores and participants' age was significant $[\mathrm{F}(1,166)=4.177, \underline{\mathrm{p}}<.05]$. Post-hoc analyses indicated that participants whose age group was 18 to 22 years $(M=3.80, S D=0.77)$ significantly had higher negotiation scores than age of over 32 $(M=3.16, S D=1.04)$. The difference between negotiation and time spent on Internet was significant $[\mathrm{F}(1,166)=3.899, \mathrm{p}<.05]$. Post-hoc analyses indicated that participants who used Internet over 4 hours a day $(M=3.81, S D=0.87)$ significantly had higher negotiation scores than who used Internet 2 to 3 hours $(M=3.22, S D=0.98)$. The difference between negotiation and time spent on social media was significant $[\mathrm{F}(1,166)=8.373, \underline{\mathrm{p}}<.01]$. Post-hoc analyses indicated that participants who spent time on social media less than 1 hour a day $(M=3.09, S D=1.02)$ significantly had lower negotiation scores than all of the other groups. Besides, an analysis of variance showed that time spent on digital game was significant on negotiation scores $[\underline{E}(1,166)=2.859, \underline{p}<.05]$. Post-hoc analyses indicated that participants who played digital game over 2 hours a day $(M=4.22, S D=0.75)$ significantly had higher negotiation scores than who did not play game $(\mathrm{M}=3.47, \mathrm{SD}=0.97)$.

With regard to total NMLs scores; participants' age was significant $[\underline{F}(1,166)=2.859, \underline{\mathrm{p}}<.05]$. Post-hoc analyses indicated that participants whose age group was 18 to 22 years $(M=3.71$, $S D=0.45)$ significantly had higher total NMLs scores than age of over $32(M=3.41, S D=0.45)$. The difference between total NMLs scores and time spent on Internet was significant $[\mathrm{E}(1,166)=2.994, \mathrm{p}<.05]$. Post-hoc analyses indicated that participants who spent time on Internet 2 to 3 hours a day $(M=3.44, S D=0.47)$ significantly had lower total NMLs scores than who spent over 4 hours $(M=3.73, S D=0.53)$. The difference between total NMLs scores and time spent on social media was significant $[\underline{F}(1,166)=6.039, \underline{p}<.01]$. Post-hoc analyses indicated that participants who spent time on social media over 3 hours a day $(M=3.80, S D=0.43$ ) significantly had higher total NMLs scores than who used less than 1 hour $(M=3.39, S D=0.55)$. At last, an analysis of variance showed that time spent on blogging was significant on total NMLs scores $[\underline{F}(1,167)=4.255, \underline{p}<.05]$. Post-hoc analyses indicated that participants who were blogging over 1 hour a day $(M=3.88, S D=0.47)$ significantly had higher total NMLs scores than who were not interested in blogging $(M=3.53, S D=0.48)$.

\section{Discussion}

The average new media literacy level of participants in the present study was medium; that is, participants were "generally new media literate" about new media environments. The situation did not differ for female and male participants. Females' new media literacy level had relatively higher than males but the difference was not significant.

The results of the present study show that there is a significant difference between new media literacy level and age group. Comparatively young participants had higher new media literacy scores than aged 32 and over. Furthermore, in terms of sub-categories, simulation, performance, appropriation, transmedia navigation and negotiation skills of young people were higher than other age groups. It may be thought that the present survey included a large variety of youth culture questions. Moreover, young Internet users aged 16-24 were heavy users of the computer and Internet in Turkey (TUIK; 2012). Cohen and Kahne (2012) also stated that substantial numbers of young people are engaging in participatory culture such as starting 
group online, circulating a blog about interest or forwarding links and videos to friends via email.

The results also show that individuals who spent more time on Internet, social media, blogging and digital game had the highest NML score. Literat (2011) reported similar findings that individuals who consume and produce new media extensively had the highest NML levels. The difference between light and heavy users of new media was especially observed in the categories of play, performance, multitasking, transmedia navigation, networking, and negotiation skills. It can be discussed that more online engagement may boost more new media literacy levels.

Female participants had lower play skill scores than their male counterparts. The result is unsurprising and should be interpreted within cultural context. The field of technology and playing an electronic device or digital game are often considered a male area and they are more chances to get acquainted with new media environment.

Critical new media literacy helps individuals develop the skills to solve problems independently and collaboratively by using the 21 st century skills. Just because these young people are digital natives, it does not mean that they do not need guidance to navigate the digital world and become digital participants.

According to Binark, Bayraktutan-Sutcu, and Bucakci (2009, p.308), critical new media literacy should be developed as a part of civic education and critical pedagogy as well. The using practices of the Internet and the digital culture should not be isolated from the macro politics of everyday life. Therefore, after providing these macro and micro political insights and the ability of critical analysis to the use of cyberspace, the individual could take the responsibility of the things that he/she does in the online world. Besides empowerment of politicized citizens, critical pedagogy and new media literacy also emphasize the responsibility of other social and political actors like family and public institutions both in the macro political level and economical contexts.

Finally, Giroux (2000) underlines the importance and the necessity of critical pedagogy and suggests that students need to learn how to read these new cultural texts critically, but they should also learn how to create their own cultural texts by mastering the technical skills needed to produce television scripts, use video cameras, write programs for computers, and produce television documentaries.

As the 21st century individuals need to learn to be digital citizens and to collaborate with others, user-generated content will be a powerful tool in the hands of individuals. Learners must be taught to be wise "prosumers" of new media and must also be equipped with the critical new media literacy skills necessary for creating it.

Additional research should be conducted in other demographic, educational, media-related characteristics, geographical areas, and cultural contexts to explore NMLs. At the same time, additional conceptual and statistical refinement of the new media literacy survey instrument for other cultural contexts should prove useful findings reported here. The scale employed in the present study is based on self-reporting so that qualitative research should be carried out in future studies. An understanding of techniques to measure the level of critical new media literacy of individuals is a crucial part of policymaking in the digital media environment. 


\section{References}

Belshaw, D.A.J. (2011). What is 'digital literacy'? A pragmatic investigation. Unpublished doctoral dissertation, Durham University, Durham, UK. Retrieved on 21 August 2012 from http://neverendingthesis.com/doug-belshaw-edd-thesis-final.pdf

Binark, M., Bayraktutan Sutcu, G., \& Bucakci, F. (2009). How Turkish young people utilize Internet cafes: The results of ethnographic research in Ankara. Observatorio (OBS*) Journal, 3(1), 286-310.

Cohen, C.J., \& Kahne, J. (2012). Participatory politics: New media and youth political action. Chicago, IL: MacArthur Network on Youth and Participatory Politics. Retrieved on 2 October 2012 from http://ypp.dmlcentral.net/sites/all/files/publications/YPP_Survey_ Report_FULL.pdf

Coiro, J., Knobel, M., Lankshear, C., \& Leu, D.J. (2008). Central issues in new literacies and new literacies research. In J. Coiro, M. Knobel, C. Lankshear, \& D. Leu (Eds.), The handbook of research on new literacies (pp. 1-21). New York, NY: Routledge.

Davies, A., Fidler, D., \& Gorbis, M. (2011). Future world skills 2020. Palo Alto, CA: Institute for the Future for Apollo Research Institute. Retrieved on 12 September 2012 from http://apolloresearchinstitute.com/sites/default/files/future_work_skills_2020_full_res earch_report_final_1.pdf

Gee, J.P. (2010). New digital media and learning as an emerging area and "worked examples" as one way forward. Cambridge, MA: MIT Press.

Giroux, H.A. (2000). Cultural politics and the crisis of the university. Culture Machine, 2, 1-23. Retrieved on 12 July 2012 from http://www.culturemachine.net/index.php/cm/ article/view/309/294

Hobbs, R. (2010). Digital and media literacy: A plan of action. Washington, DC: The Aspen Institute. Retrieved on 2 December 2011 from http://www.knightcomm.org/ wpcontent/uploads/2010/12/Digital_and_Media_Literacy_A_Plan_of_Action.pdf

International ICT Literacy Panel. (2002, May). Digital transformation: A framework for ICT literacy. Retrieved on 15 May 2012 from http://www.ets.org/Media/Tests/Information_ and_Communication_Technology_Literacy/ictreport.pdf

Jenkins, H., Clinton, K., Purushatma, R., Robison, A., \& Weigel, M. (2006). Confronting the challenges of a participatory culture: Media education for the 21st century. Chicago, IL: MacArthur Foundation. Retrieved on 12 November 2011 from http://digitallearning. macfound.org/atf/cf/\%7B7E45C7E0-A3E0-4B89-AC9C-E807E1B0AE4E\%7D/JENKINS_ WHITE_PAPER.PDF

Kellner, D. (2002). New technologies / new literacies: Restructuring education for a new millennium. In L. A. Lievrouw \& S. Livingstone (Eds.), Handbook of New Media (pp.90104). London: Sage. Retrieved on 27 February 2012 from http://pages.gseis.ucla.edu/ faculty/kellner/essays/newtechnologiesnewliteracies.pdf 
Kellner, D., \& Share, J. (2005). Toward critical media literacy: Core concepts, debates, organizations and policy. Discourse: Studies in the Cultural Politics of Education, 26(3), 369-386.

Kellner, D., \& Share, J. (2007) Critical media literacy, democracy, and the reconstruction of education. In D. Macedo \& S.R. Steinberg (Eds.), Media literacy: A reader (pp. 3-23). New York: Peter Lang.

Leu, D. J., Zawilinski, L., Castek, J., Banerjee, M., Housand, B.C., Liu, Y., \& O’Neil, M. (2007). What is new about the new literacies of online reading comprehension? In L. Rush, J. Eakle, \& A. Berger (Eds.), Secondary school literacy: What research reveals for classroom practices. (pp.37-68). Urbana, IL: National Council of Teachers of English.

Literat, I. (2011). Measuring new media literacies: Towards the development of a comprehensive assessment tool. Paper presented at Teachers College Educational Technology Conference (TCETC). New York, NY.

Livingstone, S. (2005). Media literacy - challenges ahead. Westminster Media Forum, Implementing Media Literacy: Empowerment, Participation and Responsibility. Millbank, London. Retrieved 8 July 2012 from http://eprints.Ise.ac.uk/551/1/WestminsterImplementing-Literacy.pdf

Simsek, E. \& Simsek, A. (2012, May). New literacies for digital citizenship. Paper presented at the International Conference on Communication, Media, Technolog,y and Design. Istanbul, Turkey.

TUIK. [Turkish Statistical Institute]. (2012). Hanehalkı bilişim teknolojileri araştırması. Retrieved on 15 September 2012 from http://www.tuik.gov.tr/PreTablo.do?alt_id=60

Correspondence: Jale Balaban-Sali, Assistant Professor, Faculty of Communication Sciences, Anadolu University, Yunus Emre Campus, Eskisehir, Turkey 